\title{
Evaluation of three popular diets fed to pet sugar gliders (Petaurus breviceps): Intake, digestion and nutrient balance
}

\author{
E. S. Dierenfeld (1) $\mid$ K. M. Whitehouse-Tedd (2)
}

${ }^{1}$ Ellen S. Dierenfeld, LLC, St. Louis, MO, USA

${ }^{2}$ School of Animal, Rural and Environmental Sciences, Nottingham Trent University, Southwell, Nottinghamshire, UK

\section{Correspondence}

Ellen S. Dierenfeld, Ellen S. Dierenfeld, LLC, St.Louis, MO, USA. Email: edierenfeld@aol.com

\section{Summary}

Three diets fed to 12 pair-housed sugar gliders, Petaurus breviceps, were evaluated through 5-day intake and digestion trials following 10-day transitions. Diets 1 and 2 comprised liquid formula mixes with added vegetables and fruit, and Diet 3 comprised extruded pellets and a liquid formula. Diets eaten contained $16-19 \%$ crude protein, $3 \%-15 \%$ crude fat, $10 \%-11 \%$ neutral detergent fibre, $4 \%-$ $20 \%$ starch and $8 \%-49 \%$ sugar (dry basis). Calculated individual dry matter intakes (DMI) ranged from 3.9 to $5.1 \mathrm{~g} /$ day, representing 58.2-78.4 kJ/day. DMI was greater for Diet $2(7.2 \% \mathrm{BW}) \mathrm{vs}$. Diet $1(5.6 ; p=.006)$ and Diet $3(4.2 \% \mathrm{BW} ; p=.003)$. Although these differences were no longer detectable on a MBW basis, animals were shown to have gained BW $(+14.2 \mathrm{~g} ; p=.03)$ on Diet 2 . In addition to nutrient composition differing widely among diets, DM digestibility (DMD) was higher in Diet $1(91.2 \%)$ compared to Diet $2(87.3 \% ; p=.03)$, but DMD for Diet $3(88.9 \%)$ did not differ from other diets. Gliders demonstrated ability to digest a variety of energy substrates, including simple sugars (96\%-99\%), fats (81\%-96\%) and starches (79\%-98\%), as well as substantial insoluble dietary fibre (58\%-75\%), with significant difference among diets demonstrated for some nutrients. Animals displayed selective feeding behaviours, rejecting insoluble fibre in produce and preferring the lipidcoated exterior of pellets. The diets used appeared to be balanced with respect to energy, protein and macromineral content, but may predispose to iron excess, other mineral imbalances (especially $\mathrm{Ca}$ deficiency) and obesity — clinical health issues described for pet gliders. Future focus on concentrations, types and utilization of dietary fibre in natural and captive diets, vitamin D metabolism and trace mineral interactions in sugar gliders would assist diet optimization for this highly gummivorous species.

\section{Keywords}

digestion, feeding, nutrition, Petaurus breviceps, sugar glider

\section{Introduction}

Sugar gliders (Petaurus breviceps) continue to be housed as popular small pets, particularly in the United States (USA) and Japan. In nature, and depending on the study, the consumption of plant gums (complex polysaccharides that form gels) has accounted for up to 55\% of foraging behaviour (Hume, 1999), and as much as 66\% of total intake (Nagy \& Suckling, 1985). Gliders display specialized adaptations for gummivory, including physiologic (low metabolism and low-to- moderate protein requirements) and anatomic features (gouging teeth, strong gripping claws), as well as an extensive hindgut capable of supporting fermentation (Hume, 1999; Nagy \& Suckling, 1985). They additionally consume the haemolymph and soft tissues of invertebrates (discarding the exoskeleton; supporting the notion that they should not be considered insectivores) and non-foliage plant materials (including bark and simple sugar exudates such as saps, manna, honeydew and lerp [insect excreta]), as well as nectars for energy (Smith \& Green, 1987; Hume, 1999; Dierenfeld, Thomas, \& Ives, 2006; Dierenfeld, 2009). In nature, their protein requirement is primarily satisfied by seasonal consumption 
of pollen grains, insects and other arthropods (Smith, 1980, 1982). Gums have also been shown to be an important source of dietary minerals, particularly calcium, balancing out the lack of these nutrients in simple carbohydrate-based foods, as well as most invertebrates analysed (reviewed in Dierenfeld, 2009). Thus, gliders should be considered omnivores with speciality tending towards gummivory, and ingestive behaviours highly variable depending on season and locale. Meeting both the relatively unknown nutritional requirements of the species, while encouraging naturalistic feeding behaviours utilizing available ingredients, can be a challenge in any captive feeding programme with exotic species. Concurrently, a number of health conditions with likely nutritional involvement are reported in captive sugar gliders (Ness \& Booth, 2004; Dierenfeld et al., 2006). Captive feeding recommendations for another group of exotic gummivores, Callitrichids, include the use of gum arabic (a complex polysaccharide from Old World Acacia species which also provides a source of $\mathrm{Ca}$ ) as a replacement for the natural exudates consumed as part of a natural diet (Bairrao Ruivo \& Stevenson, 2015). Gum arabic is considered to promote natural feeding behaviours (clinging, licking), as well as to provide important biochemical digestive challenges (Bairrao Ruivo \& Stevenson, 2015; Power, 1996). Additionally, there is some evidence that gum arabic may be important in treating chronic diarrhoea and associated weight loss in Geoffroy's marmoset (Callithrix geoffroyi) (Carroll, 1997; Herron, Price, \& Wormell, 2001). However, despite being readily available from pharmacies, confectionary and bakery suppliers, it appears to be only rarely included as an ingredient fed to sugar gliders. A previous evaluation of three diets commonly fed to pet gliders in the USA identified possible nutrient imbalances that may be associated with the reported health issues, including excesses of energy and protein as well as select minerals - notably $\mathrm{Ca}$ and $\mathrm{Fe}$ (Dierenfeld et al., 2006). Overfeeding calories can lead to obesity; provision of excess calories can also contribute to selective feeding on favoured (yet imbalanced) ingredients that may fulfil energy requirements before other nutrient needs are met. Excess and/or poor-quality protein intakes may manifest as altered blood metabolic or enzyme values, or weight changes. Evidence of excess dietary iron includes tissue deposition of this mineral, as well as high circulating blood concentrations and faecal excretion in sugar gliders (Dierenfeld et al., 2006). Previously reported tetanies and osteodystrophies in gliders are likely linked with imbalanced dietary concentrations of $\mathrm{Ca}, \mathrm{P}$ and/or vitamin $\mathrm{D}$ (Dierenfeld et al., 2006). Although clinical issues were not seen in the earlier (short-term) study (Dierenfeld et al., 2006), none of the diets evaluated were considered nutritionally optimal as none contained the recommended 1.5:1 to 2:1 Ca:P ratio, and blood $\mathrm{Ca}$ : $\mathrm{P}$ ratios in animals consuming them were inverse. In a subsequent review of sugar glider feeding behaviour and nutrition, a recommendation was made to develop methods and products aimed at increasing gum feeding for captive gliders in order to enhance digestive function and promotenatural behaviours (Dierenfeld, 2009). Nearly a decade later, a multitude of home-blended diet recipes as well as a greater variety of commercial products are available, but still have only limited quantitative detail regarding nutritional adequacy. At the request of the private glider-keeper community, the objectives of this study were (i) to evaluate popular diets and ingredients currently fed to captive gliders in the USA via analysis of overall nutritional balance; (ii) to assess the apparent digestibility of three diet recipes; (iii) to investigate feeding preferences for select nutrients; (iv) to qualitatively compare diets fed in captivity and their ingredients with natural diets and the evolved feeding niche of sugar gliders; (v) to qualitatively compare current dietary provision with previous findings; and lastly (vi) to evaluate current dietary provision against nutritional targets for a model species, the well-studied omnivorous laboratory rat.

\section{Materials and methods}

\subsection{Animals and housing}

Twelve adult, pair-housed non-breeding sugar gliders were utilized in the feeding studies. The six pairs were in close visual, auditory and olfactory proximity with each other. Four pairs were malefemale, with one female and one male pair, comprising a total of six study units. Animals were maintained indoors, in coated-wire cages measuring $46 \times 46 \times 75 \mathrm{~cm}\left(18^{\prime \prime} \times 18^{\prime \prime} \times 30^{\prime \prime}\right.$; WLH $)$, with a 
plastic catch tray underneath. Enclosures were furnished with flannel-lined hanging pouches, plastic hanging toys, an exercise wheel and drip bottle drinkers. Animals were exposed to normal daylight through large windows and controlled room temperature ranging from 18 to $22^{\circ} \mathrm{C}\left(65\right.$ to $\left.72^{\circ} \mathrm{F}\right)$; locations of cages were rotated weekly throughout the trials to minimize possible effects of light on appetite/activity. Gliders were weighed weekly (as pairs) on a platform scale (Model 3828, Taylor Precision Products, Las Cruces, NM, USA) to $0.1 \mathrm{~g}$. All animals remained healthy throughout the study.

\subsection{Diet treatments}

Diet 1 consisted of the Critter Love ${ }^{\circledR}$ diet plan (www.Critterlovedietcenter.com), a liquid formula fed with a chopped produce mixture. A commercial powder, Critter Love Complete $(68.0 \pm 7.2 \mathrm{~g}=1 / 2$ cup; formerly HPW Complete), manufactured for Critter Love (St. Johns, FL, USA) was blended with $358 \mathrm{ml}$ warm water, poured into ice cube trays and frozen. Main ingredients of the commercial powder included dried honey, dried egg product, dried whey protein concentrate, bee pollen, soya protein concentrate, vegetable oil, cereal grains, and vitamin and mineral premixes. One cube $(\sim 20 \mathrm{~g})$ was fed per pair of gliders, along with $\sim 44 \mathrm{~g}$ fresh or frozen mixed produce salad. Under the online diet plan, three suggested produce mixtures can be rotated; nutrient composition of these three produce blends is found in Table 1 (calculated values based on 100\% of dietary ingredients, using Zootrition $^{\mathrm{TM}}$ software; Ellen S. Dierenfeld, LLC, St. Louis, MO, USA). Only Produce Mixture One was fed in these trials, comprising the following (fresh weight): $11 \%$ frozen peas; $11 \%$ frozen cut green beans; $11 \%$ mixed frozen vegetables (carrots, lima beans,peas, green beans); $8 \%$ diced green peppers; $8 \%$ diced cucumber with skin; $25 \%$ peeled, seeded papaya; $9 \%$ frozen mixed berries (strawberries, raspberries, blackberries); 17\% chopped bok choy. All ingredients were allowed to thaw to room temperature prior to feeding. Produce Mixture Two (not used in these feeding trials) replaces the berries with apples, and the bok choy with chopped dandelion greens, while Produce Mixture Three (also not used in these trials) replaces papaya with apples and chopped, peeled cantaloupe or Tuscan melon. Diet 2 was entirely homemade and utilized the GliderKids Feeding Plan Reduced Honey Staple \#2 recipe (accessed at http://www.gliderkids-diet.com/GliderKids-FeedingPlan.html). Ingredients (fruit juice (227 ml orange juice without pulp or added Ca), honey (170 g), water (340 g), two cooked eggs (100 g), chicken or turkey jarred baby food (71 g), yoghurt (170 g), bee pollen (12 g), Wombaroo High Protein Supplement (69 g; Wombaroo Food Products, Mt. Barker, SA Australia) and calcium carbonate powder (1.2 g)) were mixed in a blender and frozen in ice cube trays to a suggested serving size of $\sim 14-\mathrm{g}$ glider per pair. The Wombaroo High Protein Supplement contains whey protein, soya protein, processed cereals, maltodextrin, dextrose, mannan oligosaccharides, $\beta$-glucans, lysine, methionine, vegetable oils, omega- 3 and omega- 6 fatty acids (including EPA and DHA), carotenoids, taurine, vitamins and minerals. Produce utilized in Diet Treatment 2 ( $60 \mathrm{~g} /$ pair) duplicated Produce Mixture One above, rather than separate portions of 15 $\mathrm{g}$ fruit and $15 \mathrm{~g}$ vegetable provided per glider as suggested by the diet plan. This change was implemented to provide a better nutrient balance from the produce portion of the diet, as well as to improve consistency between diet comparisons. Diet 3 consisted of two commercial products described in the Pocket Pets ${ }^{\mathrm{TM}}$ diet plan (www.sugargliderinfo.org), comprising 7.5 g Glide-R-Chow TM extruded pellets and $17 \mathrm{~g}$ Glide-R-Gravy ${ }^{\mathrm{TM}}$ (both products manufactured for Pocket Pets ${ }^{\mathrm{TM}}$, Goodlettsville, TN, USA) per glider pair. Pellet main ingredients include ground whole cereal grains, plant-and animal-based proteins (soya meal, flax meal, corn gluten meal, whole dried eggs, dried whey, fish meal), added minerals and vitamins as well as microbial enzymes and probiotics. The "gravy" was prepared by blending $65.3 \pm 5.5 \mathrm{~g}$ (half cup) commercial powder (containing dried honey, dried egg product, dried whey protein concentrate, bee pollen, soya protein concentrate, vegetable oil, cereal grains, vitamins and minerals) with $358 \mathrm{ml}$ (1.5 cups) warm water, and freezing portions ( $\sim 18$-g glider per pair) in ice cube trays. No other supplements or produce was fed during the trial periods. Original efforts to duplicate dry matter intakes of Diet 1 and Diet 2 (8 to $10 \mathrm{~g} / \mathrm{pair}$ ) led to excessive waste during the adaptation period of Diet 3 ; hence, amounts offered were scaled back prior 
to the intake trial period. The baseline diet on which the gliders had been habitually kept (S. Lamb, pers. comm.) comprised Diet 1. Following a 10-day adaptation period (i.e., double that required for AAFCO pet food digestibility trials, AAFCO 2007) to the new environment of the study location, the three diets were compared in 5-day intake and digestibility trials using a crossover study design where all animals received the three diets in the same sequence. All food items offered and remaining were weighed and recorded for each cage, each day. Logistical constraints prevented the randomization of diet order, with each 5-day trial separated by 10 days' adaptation to the new diet. A thick paper liner, changed daily, was placed under cage bottoms to absorb urine and drinking water during trials. All pairs emerged from their sleeping pouches between 1900 and $2100 \mathrm{hr}$ and slept continuously after $\sim 0600 \mathrm{hr}$. Fresh portions of the diets were placed in cages between 1900 and $2100 \mathrm{hr}$ daily and left overnight until the following day. Thus, the animals had access to food at all times when they were active. Between 1000 and $1300 \mathrm{hr}$ each day, all faeces and leftover foods were collected, weighed and air-dried. Inaccessible control diets were also placed near the animal enclosures during each treatment to correct for desiccation. Offered foods (both as fed and oven-dried), and oven-dried leftovers and faeces were weighed to the nearest $0.01 \mathrm{~g}$ on an analytical balance (Model ELT103, Sartorius North America TCC, Arvada, CO, USA).

\subsection{Chemical analyses}

Duplicate fresh diet samples and partially dried leftovers were oven-dried at $60^{\circ} \mathrm{C}$ to determine water content, so that per cent water and total dry matter intakes could be calculated. Other than water content, measurements and calculations were based on a dry matter (DM) basis. Dried samples of diets, selected ingredients and faeces were ground in a coffee grinder and submitted to Dairy One Forage Lab (Ithaca, NY, USA) for ash (AOAC, 2006; method 942.05), crude protein (AOAC, 2006; method 990.03), crude fat (AOAC, 2006; method 2003.05) and various carbohydrate fractions. Acid detergent fibre (ADF) was analysed using ANKOM Technology method 5 (ANKOM Technology, Macedon, NY, USA), and neutral detergent fibre (NDF) was determined using ANKOM Technology method 6 (ANKOM Technology, Macedon, NY, USA), both including residual ash; ethanol-soluble carbohydrates (simple sugars) were analysed using methods outlined by Hall, Hoover, Jennings, and Miller Webster (1999), and starch was analysed on a YSI 2700 Select biochemistry analyser (YSI Inc. Life Sciences, Yellow Springs, OH USA). The non-fibre carbohydrate (NFC) fraction was calculated as follows: $100 \%-($ ash + crude fat + crude protein $+\mathrm{NDF})$. Other water-soluble carbohydrates (WSC) were determined by difference: NFC - sugar - starch. Metabolizable energy was calculated using Atwater factors $(17 \mathrm{~kJ} / \mathrm{g}$ [4.0 kcal/g] for protein, $37 \mathrm{~kJ} / \mathrm{g}[9.0 \mathrm{kcal} / \mathrm{g}]$ for fat and $17 \mathrm{~kJ} / \mathrm{g} \mathrm{[} 4.0$ $\mathrm{kcal} / \mathrm{g}$ ] for carbohydrates). For mineral analyses, samples were digested using a CEM Microwave Accelerated Reaction System (MARS6) with MarsXpress Temperature Control in 50-ml calibrated Xpress Teflon PFA vessels with Kevlar/fibreglass insulating sleeves (CEM, Mathews, NC, USA) and then analysed by ICP using a Thermo iCAP 6300 Inductively Coupled Plasma Radial Spectrometer (Thermo Fisher Scientific Inc., Waltham, MA USA). For these measurements, pooled faecal samples, collected per cage over the course of the 5-day trials, were further combined to provide adequate quantity for analysis such that each faecal sample submitted for chemical analysis $(n=3$ diet -1$)$ represented output from two male and two female gliders allocated by similar body weights. In addition, American bee pollen, Wombaroo High Protein Supplement, Critter Love Complete, Glide-

R-Chow and Glide-R-Gravy powders were submitted to the Experiment Station Chemical Laboratories, University of Missouri (Columbia, MO, USA), for amino acid profiles, and the Diagnostic Center for Population and Animal Health, Michigan State University (Lansing, MI, USA) or Heartland Assays (Ames, IA, USA) for vitamin D3 analysis. 


\subsection{Statistics}

Data (body weight (BW (g)), metabolic body weight (kgBW0.75; MBW), DM intake as a \% of MBW, DM intake in g/MBW and nutrient digestibility were tested for normality (Shapiro-Wilk test), sphericity (Mauchly's test for sphericity) and homogeneity of variances and covariances (Box's test and Levene's test). The assumption of normality was violated for all data sets, with the exception of the majority of nutrient digestibility data which were normally distributed (although fat and $\mathrm{K}$ digestibility were also not normally distributed). Nonparametric data were therefore tested for differences between diet groups using Friedman's test, and parametric data (DMI as \% BW, digestibility data except fat and K) were tested using a repeated-measures ANOVA with sphericity assumed. Post hoc analyses were conducted using pairwise comparisons with the Bonferroni correction factor applied. Change in body weight within each diet group was tested for significance using the Wilcoxon signed ranks test. Statistical analyses were performed using SPSS (IBM Corp. Released 2012. IBM SPSS Statistics for Windows, version 22.0. Armonk, NY: IBM Corp), with significance set at $\mathrm{p}=.05$. Data are presented as mean $\pm \mathrm{SD}$, unless otherwise stated. Nutrient composition data for ingredients and whole diets were qualitatively compared among themselves, as well as to published values for earlier diets (Dierenfeld et al., 2006), the recommended nutrient intake for the best available omnivorous model species, the laboratory rat (NRC, 1995), field samples of gums and arthropods consumed by sugar gliders (Nagy \& Suckling, 1985) and previously published recommendations for sugar gliders (Booth, 2000). Amino acid composition of diets and ingredients was also compared to the amino acid profile of gum arabic (Anderson, Howlett, \& McNab, 1985). Additionally, pollen supplements available for sugar gliders were compared to pollens known to be eaten by sugar gliders in Australia (Smith \& Green, 1987; van Tets \& Hulbert, 1999) as well as other bee-collected pollens from three continents (Sommerville, 2005; Szczęsna, 2006).

\section{Results}

\subsection{Ingredient and diet analyses}

Macronutrient (water, protein, fat, ash) composition, carbohydrate fractions (sugar, starch, ADF and $\mathrm{NDF}$ ), and minerals in diets and selected individual ingredients fed to sugar gliders in this study are shown in Table 2. Once blended, the Critter Love Complete and Glide-R-Gravy solutions contained 82.5\% water, whereas the GliderKids Low Honey Staple contained 73.5\% water. Amino acid profiles for diet ingredients are found in Table 3. All diet components analysed contained a moderate protein concentration (16\%-25\% of DM), with the exception of the Wombaroo High Protein Supplement (52\% crude protein), used as an ingredient in Diet 2 . The produce mixture contributed insoluble dietary fibre, analysed as ADF and NDF. Fibre values analysed in the produce blend (20\% NDF) were similar to estimated total dietary fibre (TDF) calculated from human food values (22.5\%, Table 1); close correlation between these analytical techniques used for animal and human foods (NDF and TDF) has been previously reported (Popovich et al., 1997). The NFC in the non-produce portions of the various diets evaluated ranged from $37 \%$ of DM (Diet 3) to 75\% (Diet 1), with the produce mixture intermediate at $56 \%$ of DM. Only the Glide-R-Chow pellet used in Diet 3 contained notable levels of starch. Although the Diet 2 liquid blend contained the highest proportion of simple sugars, the produce mixture and bee pollen also analysed with substantial sugar contents (38 and 33\% of DM respectively). Glider-R Chow pellets in this study contained a considerably different nutrient profile from other dietary ingredients, containing higher starch ( 25 vs 1\%-6\% of DM), lower simple sugars (measured as ethanol-soluble carbohydrates; 3 vs $20 \%-58 \%$ of DM) and higher fat (16 vs $2 \%-5 \%$ of DM) compared with other ingredients. Apart from simple sugars and starch, other water-soluble carbohydrates (WSC) in diets (including organic acids, soluble fibre such as pectins and/or B-glucans in these diets, and longer-chain fermentable fructans and oligosaccharides), determined by difference, ranged from $8 \%$ in Glide-R- Chow to more than 50\% of DM in the Critter Love Complete and GlideR-Gravy. On a DM basis, calculated metabolizable energy content of main diet components ranged 
from $\sim 12.55 \mathrm{~kJ} / \mathrm{g}(\sim 3 \mathrm{kcal} / \mathrm{g}$ ) (produce) to $15.06-16.74 \mathrm{~kJ} / \mathrm{g}(3.6$ to $4.0 \mathrm{kcal} / \mathrm{g})$ in the non-produce portions. Mineral values were variable across ingredients, ranging twofold to 10 -fold, depending upon the nutrient considered. Calcium-to-phosphorus (Ca:P) ratios <1:1 were seen in the Critter Love Complete/Glide-R-Gravy powders as well as the bee pollen analysed, but other diet components including the non-produce portions of Diet 2 and Diet 3, as well as the produce mixture, displayed ratios between 1:1 and 2:1. Magnesium (Mg) was undetectable in the Critter Love Complete and Glide-R-Gravy powders. Not unexpectedly, the highest potassium (K) levels were analysed from the produce mixture of diets fed; vegetables and fruits are known sources of this mineral. Sodium ( $\mathrm{Na})$ values were low to moderate in all samples analysed, and undetectable in pollen. The non-produce (liquid) portions of Diet 1 and Diet 2, as well as the produce mixture, contained considerably lower concentrations of $\mathrm{Cu}, \mathrm{Fe}, \mathrm{Mn}$ and $\mathrm{Zn}$ compared to the Glide-R-Chow pellet of Diet 3, as well as by comparison to bee pollen analysed. Amino acids (AA) in select ingredients from the glider diets (Table 3) met or exceeded requirements established for growth in laboratory rats for all AA except methionine (NRC, 1995). Amino acid recovery (as a \% of analysed crude protein) of the three commercial ingredients was $96.6 \pm 0.02 \%$, which is higher than that seen in duplicate samples of the pollen analysed $(74.9 \pm 0.01 \%)$. Nonetheless, with the exception of arginine $(64 \%)$ and tryptophan (42\%), essential amino acid (EAA) concentrations found in American bee-collected pollen were similar (87\%-106\%) to averages from Australian-collected pollens (van Tets \& Hulbert, 1999; van Tets \& Whelan, 1997).Nutrient composition of total diets offered to, and consumed by, the gliders in this study is shown in Table 4, along with suggested target dietary nutrient ranges for maintenance and breeding based on a combination of information from laboratory rats (NRC, 1995), values (nitrogen, energy and Mn) measured in field samples of gums and arthropods consumed by sugar gliders (Nagy \& Suckling, 1985), and previously published recommendations for sugar gliders (Booth, 2000). Each of the diets tested met or exceeded energy and protein needs determined for sugar gliders (Hume, 1999; Nagy \& Suckling, 1985; Smith \& Green, 1987). Regarding carbohydrate fractions, all three diets contained low-to-moderate insoluble fibre (ADF and NDF); Diet 1 and Diet 2 were high in simple sugar content (32\%-49\% of DM) provided by both the produce mixture and the blended liquid formulae, whereas Diet 3 was higher in starch (20\% vs 4\%). Other WSCs varied threefold (11\%-29\%). Regarding fat-soluble vitamins, vitamin A levels were calculated according to conversion of precursor carotenoid pigments from the produce in Diet 1 and Diet 2, whereas Diet 3 contained solely pre-formed vitamin A provided in the two commercial ingredients. Diet 1 and Diet 2 contained low concentrations, and Diet 3, an adequate level of vitamin D3 compared to the target range; vitamin E concentrations were either marginally below (Diet 1 and Diet 2) or above (Diet 3) the suggested target range. Considering macrominerals, both Diet 1 and Diet 2 appeared low/marginal or imbalanced with respect to an optimal Ca:P ratio of 1.5 to 2:1 compared to Diet 3 or target ranges, while other macrominerals ( $\mathrm{Mg}, \mathrm{K}$ and $\mathrm{Na}$ ) appeared adequate across all diets. Only Diet 3 met recommended omnivore targets (laboratory rat; $\mathrm{NRC}$, 1995) for trace minerals $\mathrm{Cu}$ and $\mathrm{Mn}$, with $\mathrm{Zn}$ ranging threefold among the three diets; none were within the suggested range for dietary Fe, with Diet 1 and Diet 2 marginally low, and Diet 3 high. This same pattern was also seen for $\mathrm{Cu}$ and $\mathrm{Mn}$, with Diet 1 and Diet 2 marginal to low, and Diet 3 high. The majority of mineral nutrients ( 70\%$90 \%$ ) were provided through consumption of the produce mixture in Diet 1 and Diet 2, whereas they were primarily ( 80-95\%, except $\mathrm{Na}$ at $40 \%$ ) supplied through the pellet component of Diet 3 (Table 5). Only Diet 3 met $>60 \%$ of all EAA requirements established for breeding rats (NRC, 1995); both Diet 1 and Diet 2 were low in methionine (even summing methionine, cysteine and taurine to meet sulphur amino acid (SAA) requirements). Additionally, lysine appears to be the second limiting AA in Diet 2, meeting only $80 \%$ of established rat requirement. Despite a crude protein content only slightly greater than Diet 1 and Diet 2 (19\% vs 16 and 18\% DM, respectively), Diet 3 contained 1.5 to two times higher AA concentrations with a better quality overall AA profile. With the exception of fibre, diets consumed were nutritionally similar to diets offered. Produce portions rejected by the gliders contained the highest level of insoluble fibre (36\%). Visually, produce mixture residues comprised hulls of peas and corn kernels, and skins or peels from other vegetables and fruits; leafy green 
produce appeared to be tooth-scraped or "wadged" by chewing to remove cell contents, with more fibrous constituents remaining. Comparison of nutritional analyses between Glide-R-Chow and produce mixtures offered versus remaining (Table 2 and Figure 1) reflects contamination from urination on the leftovers (higher crude protein values) as well as selection against insoluble dietary fibre (numerically higher ADF and NDF values in orts compared to offered foods). In contrast, lower concentrations of fat and starch in leftover fractions of Glide-R-Chow and the produce mixture, and of sugar in the produce mixture, may indicate selective feeding behaviours in favour of these nutrients, even within a manufactured product such as the pellets fed here. Amino acid (AA) analysis of diets offered vs. consumed revealed little difference in AA profiles. Animals were observed manipulating and chewing the external portion of the Glide-R-Chow preferentially, possibly due to a sprayed fat coating on the extrusion.

\subsection{Body weights and intake}

Overall, animal pairs averaged $151 \pm 17 \mathrm{~g} \mathrm{BW}$ (thus, individuals averaged $75.5 \mathrm{~g}$ ) over the course of the entire study (transition plus trial periods inclusive). Given our inability to utilize a randomized order of diet presentation, starting BW (during the adaptation phase) was compared among diets and found to differ significantly $(\mathrm{p}<.01)$. Starting BW was higher for the Diet 3 trial (pair mean BW $170.5 \pm 5.37 \mathrm{~g}$ ) period compared to Diet 1 (pair mean BW $138.0 \pm 7.92 \mathrm{~g} ; \mathrm{p}<.01$ ) and also Diet 2 (pair mean BW $141.17 \pm 6.17 \mathrm{~g} ; \mathrm{p}<.001$ ). As such, change in BW (between starting BW in adaptation week and BW during testing week) was evaluated as a preferred measure of animal condition during each diet treatment. A significant change in BW was detectable for Diet 2 (increasing weight by $14.17 \pm 3.04 \mathrm{~g} ; \mathrm{p}<.01$ ) and Diet 3 (decreasing weight by $6.08 \pm 2.46 \mathrm{~g} ; \mathrm{p}$ $<.05$ ), but no change in weight was detectable while animals consumed Diet 1 (Figure 2). Animals consumed $100 \%$ of the liquid diet components, and 70\%-90\% of other constituents (dry pellet and produce mixtures respectively). Produce provided approximately $60 \%$ of DM intake in Diet 1 and Diet 2 (57 and 62\%, respectively), whereas Glide-R-Chow pellets comprised 62\% of DM intake for Diet 3. Total food intakes (as fed) were highest for the wetter diets (Diet 1 and Diet 2;64.1 2.9 $\mathrm{g} /$ day and $74.9 \pm 0.8 \mathrm{~g} /$ day, respectively) compared to Diet 3 ( $24.1 \pm 1.0 \mathrm{~g} /$ day $)$, as water dilutes nutrient concentration per unit intake. Dry matter intake (on a \%BW basis) was significantly higher on Diet $2(7.2 \pm 0.8 \%)$ compared to Diet $3(4.2 \pm 0.5 \% ; \mathrm{p}=.003)$, and also compared to Diet 1 (5.6 \pm $1.1 \% ; \mathrm{p}=.003)$. No significant difference was detectable between Diet 1and Diet 3. However, DMI on a MBW basis did not differ significantly between any diets, being $28.8 \pm 4.8 \mathrm{~g} / \mathrm{MBW}$ for Diet 1 , $37.2 \pm 3.1 \mathrm{~g} / \mathrm{MBW}$ for Diet 2 and $22.6 \pm 2.6 \mathrm{~g} / \mathrm{MBW}$ for Diet 3. Caloric intake (per individual) was highest for Diet $2(78.4 \pm 1.6 \mathrm{~kJ} /$ day $)$, compared to Diet $1(58.2 \pm 5.3 \mathrm{~kJ} /$ day; $\mathrm{p}=.001)$, as well as Diet $3(58.1 \pm 8.0 \mathrm{~kJ} /$ day; $\mathrm{p}=.006)$. Diet 1 and Diet 3 did not differ significantly in daily caloric intakes. No significant difference was detectable in ME intake between diets, being $435.3 \pm 72.5$ $\mathrm{kJ} / \mathrm{MBW}$ for Diet 1, $576.4 \pm 48.7 \mathrm{~kJ} / \mathrm{MBW}$ for Diet 2 and $368.3 \pm 42.6 \mathrm{~kJ} / \mathrm{MBW}$ for Diet 3 .

\subsection{Digestibility}

All diets were highly digestible, averaging $~ 90 \%$ apparent digestibility, which is nearly identical to that reported for free-range diets comprising gum and arthropods (88\% dry matter digestibility, $89 \%$ energy; Nagy \& Suckling, 1985). Consumption, faecal output and apparent dry matter digestibility data are presented in Table 6, with results summarized for the three diet trials. Dry matter digestibility differed among diets $(\mathrm{p}=.02)$, and post hoc tests determined Diet $1(91 \pm 2 \%)$ to be significantly higher than Diet 2 ( $87 \pm 2 \% ; \mathrm{p}=.03$ ), but no differences were detected in comparison with Diet 3 (89 $\pm 2 \%$ ). Faecal samples (Table 7) were, at times, observed to be contaminated with urine in the caging set-up; thus, apparent crude protein digestibility may be somewhat underestimated Nonetheless, protein digestibility determinations of $82 \%-85 \%$ (n.s. difference between diets) are higher (by $15 \%-$ $18 \%$ ) than values previously reported for captive sugar gliders fed higher protein diets (Dierenfeld et al., 2006), and similar to those reported on natural diets (86\%; Nagy \& Suckling, 1985), indicative of 
improvements in protein quality compared with diets offered a decade ago. No significant difference was detectable for crude fat or sugar digestion between diets. However, although an overall difference in starch digestion was detected by repeated-measures ANOVA $(\mathrm{p}<.05)$, post hoc analyses failed to detect a difference between any diets after correction for multiple comparisons was applied. Digestibility of ADF was significantly higher for Diet $1(75 \pm 2 \%)$ compared to Diet 2 $(59 \pm 2 \% ; \mathrm{p}=.04)$, but not different to Diet $3(63 \pm 2 \%)$; no difference was detectable among diets in NDF digestibility. Apparent $\mathrm{Ca}$ digestion did not differ significantly among diets, but Mg digestibility was higher for Diet $1(37 \pm 3 \%)$ and Diet $2(24 \pm 2 \%)$ compared to Diet $3(-0.4 \pm 2 \% ; p=.02$ and $p$ $=.04$, respectively), but no difference was detectable between Diet 1 and Diet 2 . Notably, P digestion was considerably lower for Diet $3(4.33 \pm 0.29 \%)$ compared to Diet $1(49 \pm 4 \%$; $<.01)$ or Diet 2 (54 $\pm 2 \% ; \mathrm{p}<.01)$. No significant differences were detectable in pairwise comparisons between diets in $\mathrm{K}$ or Na digestibility, despite detection of an overall difference through ANOVA for $\mathrm{Na}(\mathrm{p}<.01)$.

Negative digestibility coefficients for $\mathrm{Cu}$ were found for all diets, with no detection of significant differences among diets. A significant difference in Fe digestibility was detected between Diet $2(22 \pm$ $2 \%)$ and Diet $3(-30 \pm 0.3 \% ; \mathrm{p}<.01)$. Zn digestibility was higher in Diet $2(18 \pm 2 \%)$ compared to Diet $3(-15 \pm 3 \% ; \mathrm{p}<.01)$.

\section{Discussion}

All three diets evaluated in this study have been reportedly used for long-term ( $>3$ to 5 years) maintenance of captive sugar gliders in multiple locations (P. Brewer, S. Sterk, V. Klunder, pers. comm), albeit with no published documentation of nutrient composition or associated health status. Each of the diets utilized was found to be highly palatable; a variety of carbohydrates $(\mathrm{CHO})$ were likely effectively utilized through a combination of digestive as well as fermentative capabilities targeting simple sugars and starches (endogenous enzymes), or more complex polysaccharides (microbial breakdown of soluble and insoluble fibre fractions). All study animals appeared healthy throughout the current study, and none were considered over-or underconditioned (weight range 59 to $95 \mathrm{~g} ; \mathrm{n}=12$ individuals).

\subsection{Caloric Intake}

Gliders appeared to modulate intakes at $\sim 65 \mathrm{~kJ}(\sim 15 \mathrm{kcal})$ day -1 individual-1, which is in accordance with generic energetic equations for marsupial basal metabolic rate (BMR; where $2 \mathrm{X} B M R=\sim 54 \mathrm{~kJ}$ (13 kcal) day-1 for maintenance activity of a typical 70-g free-ranging glider) (Hume, 1999; Nagy \& Suckling, 1985). Captive adult gliders at maintenance consumed one-half to one-third fewer calories during this study compared with previous data reported for growing (3X BMR) males (101-147 $\mathrm{kJ} /$ day; 24 to $35 \mathrm{kcal} /$ day), with an average weight $98 \mathrm{~g}$ (Dierenfeld et al., 2006). Although clearly growing animals require higher energy intake to support growth and activity compared with adults, size comparisons with the earlier study suggest a tendency towards smaller body size in the current pet glider population. It remains to be determined whether this apparent smaller stature simply reflects a lower obesity rate, or is linked with lower growth rates due to underlying nutritional issues, presents as an artefact of artificial selection via certain breeding lines, or is a combination of factors. Obesity Has been previously considered a health problem for this species in captivity; awareness of the need to maintain a healthy body weight (dictated by individual conformation), particularly for marsupials with low basal metabolism and the ability to further conserve energy through torpor (Hume, 1999), is critical in supplying appropriate meal size and nutritional adequacy relative to energy density. In light of this, our findings regarding Diet 2, which appeared to have a greater potential to lead to obesity if fed as the sole source of nutrition long term compared to either Diet 1 or Diet 3, warrant consideration. The higher caloric intake (on an individual, but not MBW, basis) determined for this diet was associated with a significant increase in body weight during its feeding period. Although animals had a significantly higher BW on Diet 3, this is explained as a consequence of the sequential diet exposure and/or due to the initial overfeeding that occurred as a result of attempts to duplicate 
DMI among dietary treatments. The finding that animals exhibited no change in BW while on Diet 1 , and actually lost weight while on Diet 3 (although some of this may be due to the adjusted feeding regime implemented to prevent overfeeding), parallels findings in caloric intake. Diet 2 may also have been less nutritionally balanced compared with Diet 1 , with its lower concentrations of all amino Acids and crude fat content, and higher level of more rapidly digestible simple sugars, the latter potentially explaining the higher DM intake (i.e., selection for sugar). Observationally, animals appeared calmer, perhaps more satiated, when feeding on Diet 3; its lower WSC and sugar content, combined with the higher fat content and nutrient density, may have resulted in a lower glycaemic index and/or slower rate of utilization (Brand-Miller, Holt, Pawlak, \& McMillan, 2002; Romano et al., 2014; Storlien et al., 2000). A previous study investigating a natural diet comprising gums and arthropods (DM basis $66 \%$ gum, $34 \%$ invertebrates, $1 \%$ bark) determined it contained $44 \%$ water; gliders ate approximately $16 \%$ of BW on a fresh basis and approximately $9 \%$ on a DM basis (Nagy \& Suckling, 1985). By contrast, captive diets in this study were $64 \%-87 \%$ water, suggesting they may be more dilute than necessary. As all gliders have access to water bottles on an ad libitum basis, water content of provisioned diets is less critical for meeting water turnover needs; more nutrient-dense, drier diets may therefore be suitable to support gut as well as oral health in this species. Drier diets may also be associated with slower passage rates, allowing for higher fermentation potential, and additionally have been shown to promote better dental hygiene in domestic pet species (Gawor et al., 2006).

\subsection{Carbohydrate intake}

Although specific carbohydrase enzyme studies have not been conducted, three main sugarsglucose, fructose and sucrose - are found in plant nectars, and many Banksia spp. (known to be eaten by gliders) have sucrose-dominated nectars (Nicholson \& Van Wyk, 1998). It follows that the gliders are considered to possess sufficient sucrose enzyme activity to hydrolyse sucrose to its monosaccharide components glucose and fructose (the latter two comprising major sugars in honey). These sugars also encompass the main simple carbohydrates (CHOs) of domestic fruits and vegetables (Li, Andrews, \& Pehrsson, 2002). The high sugar level analysed in the bee-collected pollen in this study is likely an artefact from nectar or honey added by the bees to their pollen packets, accounting for up to $40 \%$ of total pollen dry weight; bee-collected pollens have been shown to contain as much as 10X higher sugar concentrations compared with those that were hand-collected (Roulston \& Cane, 2000). Thus, while included in some blended diets as a "natural" ingredient, these pollens may differ considerably in nutrient composition compared to those encountered by gliders in nature. Moreover, the added sugar dilutes the amino acid and mineral constituents that may otherwise be supplied through pollen consumption in nature. While individual sugar moieties were not analysed, simple sugars were almost completely digested in all diets, despite ranging widely from $~ 10$ to almost $50 \%$ of dietary DM. Other WSCs varied threefold (11\%-29\%) and likely represent a combination of both digestible and fermentable carbohydrates which the gliders are capable of utilizing for energy. The ability to ferment insoluble fibre was demonstrated in the current study; ADF and NDF disappearance ranged from $\sim 60$ to $75 \%$ in these trials, albeit low dietary fibre levels ( $<10 \%$ of DM), and the very small sample sizes may contribute to a higher incidence of laboratory artefact contributing to these results. DM digestibility of $92 \%$ has been reported in sugar gliders fed a gumonly diet (Smith, 1980), further supporting fermentative ability of sugar gliders. Given the high proportion of gums included in free-range glider diets, proper fibre sources - either soluble or insoluble - should be considered essential in the diets of captive sugar gliders. The absence of gums from the popular diets evaluated here warrants consideration in future diet formulations.

\subsection{Protein intake}

According to the requirements calculated by Smith and Green (1987), the 70-g animals in this study were estimated to require 150 to $200 \mathrm{mg}$ crude protein to support maintenance and normal activity. 
All diets, as consumed, more than met this minimal level of protein: Diet 1 averaged $628 \mathrm{mg}$ protein consumed, Diet 2, $919 \mathrm{mg}$ and Diet 3,745 mg individual per glider; levels that would likely also support physiologic states of growth, lactation and reproduction. Although still higher than calculated recommendations, these values are less than half those fed a decade ago (1,330 to 2,270 mg) to 90-to 105-g growing gliders (Dierenfeld et al., 2006), representing an improved feeding regime. Future diet formulations might therefore benefit from further reduction in crude protein content. Amino acid recovery of the three commercial ingredients evaluated in the current study was higher (97\%) than the pollen analysed (75\%), suggesting that a portion of pollen grains used as ingredients in some diet blends may include non-protein nitrogen sources, as has been previously reported (Rabie, Wells, \& Dent, 1983). While highly digestible (up to 76\%; Smith \& Green, 1987), pollens also appear to be limiting in methionine content. However, the taurine (typically only found in animal proteins) concentrations determined in pollens may increase the protein value of pollens significantly. American bee-collected pollen can be considered an appropriate protein source with high biological value for marsupials, especially given the similarity between EAA concentrations in American beecollected pollen and pollens collected in sugar gliders' native range (Australia) (van Tets \& Hulbert, 1999 ; van Tets \& Whelan, 1997) as identified in the current study. When total diet composition is considered, Diet 1 still requires additional methionine but otherwise provides the most suitable AA ratio for omnivorous species with the least overage. Diet $3 \mathrm{AA}$ ratios, although $\sim 10 \%-30 \%$ higher than optimal ranges, are not considered levels that would result in detrimental imbalances; in fact, the slightly elevated arginine content may provide an essential precursor for more efficient metabolism of other AAs through the urea cycle, as has been shown in other species (Ball, Urschel, \& Pencharz, 2007). Further, Diet 3 represents the only diet that meets target sulphur AA concentrations (combining cysteine + methionine + taurine) for rat reproduction and growth (NRC, 1995). Given the quality and balanced proteins of this particular diet, overall crude protein and AA acid levels could be safely and considerably reduced, particularly for meeting maintenance protein requirements. Diet 2 EAA ratios, in general, fall intermediate to Diet 1 and Diet 3 but are lowest in methionine as well as total SAAs. A potential dietary supplement advocated for use in captive gummivore diets is plant gums (Bairrao Ruivo \& Stevenson, 2015). In a study of AA composition in Acacia senegal gums, Anderson et al. (1985) documented low (1.5\%-3\%) total protein, poor EAA content and balance, and limiting sulphur amino acids, suggesting that gum arabic should not comprise the majority of a captive sugar glider's diet. It may, however, provide a low-protein diet supplement of benefit to feeding behaviours and possibly gut health without contributing to already higher than recommended protein levels found in the popular captive diets evaluated to date. Until further data suggest otherwise, captive diets should be formulated to meet adequate AA concentrations established for the laboratory rat model, as well as to reflect ideal AA ratios.

\subsection{Vitamin and mineral intake}

No work has been conducted on vitamin requirements of sugar gliders. Essential fatty acids as well as sterols have been identified in the ether extracts of both pollens (Roulston \& Cane, 2000) and invertebrates (Finke, 2015), but both food types are in general considered poor sources of fat-soluble vitamins, containing undetectable levels of pre-formed vitamins A and K. Pollen analysed in this study contained a vitamin D3 level below detection limits of the laboratory $(<0.5 \mathrm{ng} / \mathrm{g})$, but measurable D2 at $1.2 \mathrm{ng} / \mathrm{kg}$, which converts to a vitamin D2 content of $48 \mathrm{IU} / \mathrm{kg}$. Further, some insects have been reported to contain vitamin D and E levels (Finke, 2015) that encompass adequate requirement ranges for both growing rats and chicks. Thus, both pollen (albeit low) and insects may be sources of dietary vitamin D, and invertebrates, a source of vitamin $\mathrm{E}$ for gliders in nature. The vitamin D3 levels in captive diets measured in commercial products and blends, with no contribution from domestic produce considered, ranged widely in this study from 0.2 to $0.7 \mathrm{IU} / \mathrm{g} \mathrm{DM}$ ), with only Diet 3 considered adequate, based on estimates from both domestic model species and natural food ingredient composition. This study was not designed specifically to measure mineral balance, nor was urinary excretion accounted for. Nonetheless, variable apparent digestibility of macrominerals $(\mathrm{Ca}$ 
[28\%-38\%]; $\mathrm{Mg}$ [0\%-37\%]; P [4\%-54\%]; K [75\%-84\%]; and $\mathrm{Na}$ [94\%-97\%]) suggests that differences in dietary levels, nutrient interactions and/or specific ingredients may substantially impact mineral nutrition. Further, as $\mathrm{Na}$ and $\mathrm{K}$, at least, are under tight renal regulation, faecal measurements of these nutrients are neither elaborated nor particularly relevant. The extremely low or negative digestibility measured in trace minerals ( $\mathrm{Cu}[-59 \%$ to $-128 \%]$; Fe [ $-30 \%$ to $22 \%]$; $\mathrm{Mn}[-19 \%$ to $15 \%]$; $\mathrm{Zn}$ [-15\% to $18 \%]$ ) may indicate poor bioavailability, or insufficiency of dietary levels of these nutrients. The excretion in faeces of amounts higher than intake results presumably from endogenous losses. Conversely, these findings may indicate higher than needed levels are supplied through the diet, with excesses not absorbed and simply excreted, or indicate some type of chemical binding such that minerals are less biologically available, and/or reflect environmental contamination from the caging substrate or animal grooming activities. Interestingly, Nagy and Suckling (1985) utilized Mn as an assumed unabsorbed internal digestibility marker in their field studies of sugar glider energetics, with diet samples averaging $\sim 4 \mathrm{mg} / \mathrm{kg}$ and faecal samples averaging $339 \mathrm{mg} / \mathrm{kg}$ (DM basis). These values are almost identical to those of Diet 3 in this study, lending support to the poor bioavailability of this mineral in sugar gliders. While specific mineral nutrition/metabolism of sugar gliders has not been examined in detail, health issues potentially caused by $\mathrm{Ca}$ and $\mathrm{P}$ imbalances (Dierenfeld et al., 2006) in captive gliders are still reported (Jones \& Tully, 2012). With the exception of dark leafy greens, domestically grown fruits and vegetables should be considered poor sources of dietary Ca, and generally imbalanced with respect to optimal Ca:P ratios. Moreover, both insoluble and soluble fibres can chemically bind minerals and affect bioavailability; the higher mineral concentrations measured in the more fibrous discarded portions of the produce mixture blend offered to sugar gliders in the current study may reflect this tendency. Therefore, produce must be appropriately supplemented, whereby blended produce mixtures should be carefully formulated to maximize nutrient balance (taking into account the potential for selective feeding behaviours). Of the three diet treatments in this study, proper $\mathrm{Ca}$ and $\mathrm{P}$ concentrations and ratios were provided only by Diet 3. Diet 1 and Diet 2, comprising approximately $60 \%$ of DM intake from produce, were both low in Ca relative to $\mathrm{P}$, and high in K, characteristic of domestic fruits. Other mineral interactions must also be considered - for example, high dietary $\mathrm{K}$ can increase $\mathrm{Na}$ requirement through increased absorption, but also can reduce $\mathrm{Mg}$ absorption (Puls, 1994). A maximal dietary $(\mathrm{Ca}+\mathrm{Mg})$ : $\mathrm{K}$ ratio of 1: 2.2 has been recommended for herbivorous livestock (Puls, 1994); only Diet 3 falls under that threshold. Whether this ratio is a reasonable guideline for glider diets remains to be determined, but serum $\mathrm{K}$ levels for gliders considered healthy $(3.3 \pm 0.7(\mathrm{n}=5), 4.6-5.5 \mathrm{mEq} / \mathrm{L}(\mathrm{n}=93)$; Brust \& Pye, 2013) are within the normal range established for domestic species and livestock (2.4-6.0 mEq/L; Puls, 1994). Mg and $\mathrm{Na}$ in all three diets were within target nutrient ranges; differences in apparent mineral digestibility detected may reflect ingredient matrix effects or possibly metabolic imbalances. Trace mineral imbalances are also suggested from these studies. Separate from the low $\mathrm{Cu}$ levels determined in Diet 1 and Diet 2, a dietary ratio of $\mathrm{Cu}: \mathrm{Zn}>1: 4$ (indicating excess $\mathrm{Zn}$ ) can lead to $\mathrm{Cu}$ binding (Davis \& Mertz, 1987). The negative apparent $\mathrm{Cu}$ digestibility for all diets may reflect such a mechanism; $\mathrm{Cu}: \mathrm{Zn}$ ratios were high for all diets in this study (1:5.7 [Diet 3] to 1:9.7 [Diet 2]). Excess dietary protein can also decrease Cu availability (Davis \& Mertz, 1987; Puls, 1994). Anecdotal reports of reversible aberrant hair pigmentation in sugar gliders (Brewer, pers comm) may be linked to copper status as conversion of the AA tyrosine to melanin is catalysed by Cu-dependent enzymes (Davis \& Mertz, 1987). Diet 3 contains higher Fe concentrations compared with Diet 1 and Diet 2, with values outside suggested ranges for this nutrient, which is of potential concern. Further biochemical evaluation of trace mineral status in gliders - both captive and free-ranging — may help elucidate more optimal dietary concentrations and combinations for this species.

\subsection{Suitability of domestic produce for sugar gliders}

The three produce mixtures analysed in Table 1 met estimated recommended target nutrient levels for only vitamin $\mathrm{E}, \mathrm{Na}$ and $\mathrm{Fe}$; all are low in $\mathrm{Ca}$ content, high in $\mathrm{K}$ and marginal to low in remaining minerals. Total crude protein concentration may appear adequate, but amino acid balance can be 
insufficient in produce-based diets - and particularly so in fruits. Vegetables supply $90 \%-95 \%$ of total methionine (the main limiting EAA identified by this study) in these blends, with more than half from legumes (peas and beans; data not shown). As described, the blends average approximately $52 \%$ vegetables, $34 \%$ fruits and $14 \%$ leafy greens (fresh weight basis). While not nutritionally optimal, these blends nonetheless provide a better nutritional balance compared to solely offering fruits, or 50:50 offering of fruits:vegetables (a suggestion of Diet 2 not implemented in this study). Given that sugar gliders are not frugivores, diets containing such high proportions of fruit are not advised. The carbohydrate complement of vegetables, specifically legumes and leafy greens containing both soluble and insoluble fibre, may better duplicate nutrient profiles of natural plant materials consumed by sugar gliders. Therefore, if mixed produce is fed, a suggested ratio of 55\% vegetables, $30 \%$ dark leafy greens, with no more than $15 \%$ fruits (all fresh weights) will increase protein quality and mineral profiles in blends fed to gliders and provide a closer fit with natural diets.

\subsection{Dietary evaluation of three popular recipes}

Actual laboratory analysis of the produce blend used in the feeding trials agrees well with calculated values. Other primary diet constituents (Critter Love Complete or GliderKids Reduced Honey Staple), consumed with produce in a 40:60 ratio (DM basis), altered total dietary nutrient balance to increase fat and crude protein, decrease fibre and reduce $\mathrm{Cu}, \mathrm{Fe}$ and $\mathrm{Mn}$ concentrations by $35 \%-50 \%$. Compared with feeding solely on produce, addition of the Critter Love Complete (Diet 1) reduced sugar content of the overall diet, whereas the GliderKids blend (Diet 2) increased dietary sugar. The combination of low-nutrient-density Glide-R-Gravy and high-nutrient-density Glide-R-Chow (Diet 3) resulted in a high vitamin $\mathrm{E}$, high $\mathrm{Fe}$ and high $\mathrm{Zn}$ diet that otherwise fits within all defined target nutrient ranges. Without detailed analytical data that are often not provided on ingredient labels, or sometimes even in databases developed for human foods, it can be difficult to self-formulate nutritionally balanced diet blends. For the long-term health and welfare concerns of pet sugar gliders, the findings of the current study suggest that the use of home-blended recipes, particularly as a staple diet, is to be discouraged (as are volumetric measures rather than more accurate weights in describing these diets). Apart from nutrient composition of specific diets, physical form may also be an important component that should be considered in optimal captive diet development to support natural feeding behaviours, as well as oral and gastrointestinal health. Further studies of the ability of gliders to ferment different types and amounts of dietary fibre are strongly encouraged.

\subsection{In situ feeding ecology}

A calculated dietary nutritional profile based on natural food ingredients may provide useful feeding guidelines for sugar gliders moving forward. Although the variety of forms and ingredients utilized in captive feeding programmes confirms the adaptability/flexibility of this species ecologically, anatomically and physiologically, sugar gliders are adapted for a high level of exudativory (Hume, 1999). One field study in mixed eucalypt habitat described ingestive behaviours (averaged over 12 months), with gliders reported feeding on Acacia spp. Gums $\sim 40 \%$ of time, gleaning leaves and peeling bark (presumably seeking invertebrates) $~ 30 \%$ of time, eating Eucalyptus spp. sap 15\% of time and licking branches $\sim 10 \%$ of time (Smith, 1982). A second study, in a different location (coastal woodland heath), reported food choices including (again averaged over $12 \mathrm{mo}$ ) 50\% eucalypt flowers, $~ 30 \%$ feeding on Banksia nectar or sap, 15\% Acacia spp. gum and $~ 5 \%$ insects (Howard, 1989). A third investigation (van Tets \& Whelan, 1997) described faecal volume from gliders as containing approximately $40 \%$ invertebrate remains, 35\% remains of flowers and leaves, $20 \%$ pollen grains (65\% empty, primarily Banksia spp.) and 5\% unidentified material. However, it must be noted that certain dietary items (e.g., gums) cannot be detected in faecal matter, and digestibility of items varies dramatically between ingested items, such that dietary intake based on faecal data alone must be interpreted with caution. Finally, a short-term study (1-week period) that included stomach content evaluation documented dietary proportions of $49 \%$ arthropods, $48 \%$ gum and $3 \%$ tree bark (Nagy \& 
Suckling, 1985). While feeding behaviours and faecal sampling are not direct measures of intake, useful correlations with intake have been described for a number of non-human primates, including gummivores (Cabana, Dierenfeld, Donatti, \& Nekaris, 2015; Conklin-Brittain,Knott, \& Wrangham, 2001). Full pollen grains and insoluble fibre fractions of invertebrates and plants in faeces represent less digestible dietary components $(\sim 35 \%-40 \%)$; when weighted proportionately, combining these various studies yields an estimated "natural" diet for sugar gliders comprising approximately $30 \%$ gum, $25 \%$ flowers, $20 \%$ nectar/sap, $15 \%$ invertebrates and $10 \%$ pollen. It is unclear whether reported feeding on flowers by free-ranging sugar gliders represents selection for nectar, pollen, petals or a combination (complete inflorescence); smaller feather-tailed gliders (Acrobates pygmaeus) have a tongue anatomy adapted for targeted nectar consumption when feeding on flowers (Herrmann et al., 2013), a specialization not seen in Petaurus. Nonetheless, captive sugar gliders consume various edible floral parts including entire flowers or primarily pollen, depending upon the species of plant ( $\mathrm{P}$. Brewer, pers. comm.). Thus, utilizing limited nutrient information on Acacia spp. gums (Nagy \& Suckling, 1985), Australian flowers (entire; Herrmann et al., 2013), artificial nectar (Herrmann et al., 2013), moths (Finke, 2015) and bee pollen (van Tets \& Hulbert, 1999; van Tets \& Whelan, 1997), a diet comprising these percentage ingredients would roughly contain (DM basis) the following: 15.5\% crude protein, $4.5 \%$ crude fat, $10.5 \%$ NDF and $3 \%$ ash, with a calculated NFC of $\sim 70 \%$ and ME = $16.3 \mathrm{~kJ} / \mathrm{g}(3.9 \mathrm{kcal} / \mathrm{g})$. Of the diets tested here, all provided marginally greater $\mathrm{CP}(16.3 \%-19.4 \%)$, and ash $(4.1 \%-5 \%)$, but slightly lower crude fat (2.6\%-3.6\%, with the notable exception of Diet 3 which contained $15 \%)$, and NFC (64\%-51\%), with all three having similar NDF content $(9.7 \%-11.1 \%)$ and ME (15.1-16.3 kJ/g; Table 4) compared to the calculated "natural" intake. The moderate protein concentration calculated from in situ feeding studies may represent an overestimation of true protein intake due to the non-protein nitrogenous content of some dietary ingredients, although in the absence of further research, a low-moderate protein requirement still appears appropriate for this species. Of the NFC component, approximately half of total diet (30\%-35\% of DM) would comprise indigestible carbohydrates that require microbial fermentation, with the remainder digestible sugars $(35 \%-40 \%$ of DM). Mineral concentrations calculated from this hypothetical "natural" diet can be considered underestimates (due to available information from partial ingredients only - the gums, insect and pollen). Additional non-food sources of minerals could also be available in nature including soil, stones, clay or bark licks, wood and eggshells. Regardless, proportional composition results in calculated dietary ranges and ratios $(\mathrm{Ca}(0.5 \%), \mathrm{Mg}(0.1 \%), \mathrm{K}(0.3 \%), \mathrm{P}(0.2 \%) ; \mathrm{Cu} 3 \mathrm{mg} / \mathrm{kg}, \mathrm{Fe} 81$ $\mathrm{mg} / \mathrm{kg}$, Mn $23 \mathrm{mg} / \mathrm{kg}$, Se $0.1 \mathrm{mg} / \mathrm{kg}$, Zn $27 \mathrm{mg} / \mathrm{kg}$ ) that approximate mineral requirements established for the laboratory rat (Table 4). These suggested target nutrient ranges for sugar gliders can be validated with physiologic measures of nutritional status, but in the interim indicate that, of the three diets tested, Diet 3 had the most appropriate vitamin and mineral profile. The current diets evaluated appear to, in general, oversupply protein relative to established $\mathrm{N}$ requirements, with some indication of potential SAA imbalance. Low fibre levels in captive diets, and a total lack of soluble fibre from gums, likely do not challenge the potential fermentative ability of the gliders. Trace mineral nutrition, particularly $\mathrm{Cu}$, warrants more detailed investigation. The use of these diets to support health long term and throughout growth, reproduction and lactation life stages also remains to be determined. Compared to diets evaluated previously for captive pet gliders, (Dierenfeld et al., 2006), macromineral balance, particularly $\mathrm{Ca}$ and $\mathrm{P}$, appears better addressed in current popular diets through the use of better formulated complete diets and/or blends (both mixed produce and supplements). Likewise, less reliance on nutritionally imbalanced insects in the diet is reflected in current diet trends, as are smaller meal sizes/portions and a recognition of the importance of maintaining appropriate body condition/weights. Until actual requirements have been established, recommended targets based upon the laboratory rat provide a useful model against which to evaluate captive sugar glider diets due to the omnivorous feeding habits and hindgut caecal fermentation ability of both species. 


\section{Acknowledgements}

We would like to particularly thank Shelly Sterk and the Sugar Glider Foundation for securing the funding to support these studies - her dedication to increasing knowledge and welfare of sugar gliders is a shining example. Thanks to Sherri Lamb for donation of the study animals, and all the private donors who contributed funding to the project. Conversations with, and information provided by, Janine Perlman, Peggy Brewer, Virgil Klunder, Jim Nutter, Gordon Rich, David Brust and Doug Pernikoff greatly enhanced the content and quality of this report, as did comments from Marcus Clauss and two anonymous reviewers. The authors declare no conflict of interests.

\section{References}

AAFCO. (2007). AAFCO dog and cat food metabolisable energy protocols. In Official Publication Association of American Feed Control Officials Inc. 2011: 175-180.

Anderson, D. M. W., Howlett, J. F., \& McNab, C. G. A. (1985). The amino acid composition of the proteinaceous component of gum Arabic (Acacia Senegal (L.) Willd.). Food Additives and Contaminants, 2, 159-164.

AOAC. (2006). Official methods of analysis, 17th edn. Arlington, VA:Association of Official Analytical Chemists.

Bairrao Ruivo, E., \& Stevenson, M. F. (Eds.) (2015). EAZA best practice guidelines for Callitrichidae. France: ZooParc de Beauval.

Ball, R. O., Urschel, K. I., \& Pencharz, P. B. (2007). Nutritional consequences of interspecies differences in arginine and lysine metabolism. Journal of Nutrition, 117, 1626S-1641S.

Booth, R. J. (2000). General husbandry and medical care of sugar gliders. In J. D. Bonagura (Ed.), Kirk's current veterinary therapy XIII (pp. 1157-1163). Philadelphia, USA: WB Saunders.

Brand-Miller, J. C., Holt, S. H. A., Pawlak, D. B., \& McMillan, J. (2002). Glycemic index and obesity. American Journal of Clinical Nutrition, 76(Suppl.), 281S-285S.

Brust, D. M., \& Pye, G. (2013). Sugar gliders. In J. W. Carpenter \& C. J. Marion (Eds.), Exotic animal formulary, 4th edn (pp. 439-454). St. Louis, USA: Elsevier.

Cabana, F., Dierenfeld, E., Donatti, G., \& Nekaris, K. A. I. (2015). Stronger than yesterday: new nutrient recommendations for lorisine primates. In H. Bissell \& M. Brooks (Eds.), Proceedings of the AZA nutrition advisory group. Portland, OR, USA.

Carroll, J. B. (1997). A comparative summary of the nutritional adaptations and needs of callitrichids and application to captive management. In C. Pryce, L. Scott, \& C. Schnell (Eds.), Marmosets and tamarins in biological and biomedical research (pp. 70-77). Salisbury, UK: DSSD Imagery.

Conklin-Brittain, N. L., Knott, C. D., \& Wrangham, R. W. (2001). The feeding ecology of apes. In: The apes: Challenges for the 21st century (pp. 167-174). Conference Proceedings, May 10-13, 2000. Brookfield, IL:Brookfield Zoo.

Davis, G. K., \& Mertz, W. (1987). Copper. In W. Mertz (Ed.), Trace elements in human and animal nutrition, 5th edn (pp. 301-364). San Diego, USA:Academic Press.

Dierenfeld, E. S. (2009). Feeding behavior and nutrition of the Sugar Glider (Petaurus breviceps). Veterinary Clinics of North America: Exotic Animal Practice, 12, 209-215. 
Dierenfeld, E.S., Thomas, D., \& Ives, R. (2006). Comparison of commonly used diets on intake, digestion, growth and health in captive sugar gliders (Petaurus breviceps). Journal of Exotic Pet Medicine 15, 218-224.

Finke, M. D. (2015). Complete nutrient content of three species of wild caught insects, pallid-winged grasshopper, rhinoceros beetles, and white-lined sphinx moth. Journal of Insects for Food and Feed, 1, 281-292.

Gawor, J. P., Reiter, A. M., Jodkowska, K., Kurski, G., Wojtacki, M. P., \& Kurek, A. (2006). Influence of diet on oral health of cats and dogs. Journal of Nutrition, 136, 2021S-2023S.

Hall, M. B., Hoover, W. H., Jennings, J. P., \& Miller Webster, T. K. (1999). A method for partitioning neutral detergent soluble carbohydrates. Journal of the Science of Food and Agriculture, 79, 2079-2086.

Herrmann, E. A., Herrin, K. V., Gleen, W., Davies, P., Stapley, R., Stebbings, V., ... Chaves, A. V. (2013). Partial replacement of an artificial nectar diet with native browse for feather-tail gliders (Acrobates pygmaeus) in captivity. Zoo Biology, 32, 394-399.

Herron, S., Price, E., \& Wormell, D. (2001). Feeding gum Arabic to New World monkeys: Species differences and palatability. Animal Welfare, 10, 249-256.

Howard, J. (1989). Diet of Petaurus breviceps (Marsupialia: Petauridae) in a mosaic of coastal woodland and heath. Australian Mammalogy, 12, 15-21.

Hume, I. D. (1999). Marsupial nutrition. Cambridge, UK: Cambridge University Press.

Jones, K. L., \& Tully, T. N. Jr (2012). Diagnostic challenge. Journal of Exotic Pet Medicine, 21, 354357.

Li, B. W., Andrews, K. W., \& Pehrsson, P. R. (2002). Individual sugars, soluble and insoluble dietary fiber contents of 70 high consumption foods. Journal of Food Composition and Analysis, 15, 715723.

Nagy, K. A., \& Suckling, G. C. (1985). Field energetics and water balance of sugar gliders, Petaurus breviceps (Marsupialia, Petauridae). Australian Journal of Zoology, 33, 683-691.

Ness, R. D., \& Booth, R. (2004). Sugar gliders. In K. E. Quesenberry \& J. W. Carpenter (Eds.), Ferrets, rabbits and rodents clinical medicine and surgery, 2nd Edn (pp. 330-338). Saint Louis, MO, USA: Elsevier Inc.

Nicholson, S. W., \& Van Wyk, B.-E. (1998). Nectar sugars in Proteaceae: Patterns and processes. Australian Journal of Botany, 46, 489-504.

NRC (National Research Council). (1995). Nutrient requirements of laboratory animals. Washington, DC, USA: National Academy Press.

Popovich, D. G., Jenkins, D. J. A., Kendall, C. W. C., Dierenfeld, E. S., Carroll, R. W., Tariq, N., \& Vidgen, E. (1997). The western lowland gorilla diet has implications for the health of humans and other hominoids. Journal of Nutrition, 127, 2000-2005.

Power, M. L. (1996). The other side of callitrichine gummivory - digestibility and nutritive value. In M. A. Norconk, A. L. Rosenberger, \& P. A.

Garber (Eds.), Adaptive radiations in neotropical primates (pp. 97-110). New York: Plenum Press.

Puls, R. (1994). Mineral levels in animal health (2nd edn). Clearbrook, BC, Canada: Sherpa International. $356 \mathrm{pp}$. 
Rabie, A. L., Wells, J. D., \& Dent, L. K. (1983). The nitrogen content of pollen protein. Journal Apicultural Research, 22, 119-123.

Romano, A., Karimian Azari, E., Tempesta, B., Mansouri, A., Micioni Di Bonaventura, M. V., Ramachandran, D., ... Gaetani, S. (2014). High dietary fat influences the activation of specific hindbrain and hypothalamic nuclei by the satiety factor oleoylethanolamide. Physiology \& Behavior, $136,55-62$.

Roulston, T. H., \& Cane, J. H. (2000). Pollen nutritional content and digestibility for animals. Plant Systematics and Evolution, 222, 187-209.

Smith, A. P. (1980). The diet and ecology of Leadbeater's possum and the sugar glider. PhD Dissertation, Monash University.

Smith, A. P. (1982). Diet and feeding strategies of the marsupial sugar glider in temperate Australia. Journal of Animal Ecology, 51, 149-166.

Smith, A. P., \& Green, S. W. (1987). Nitrogen requirements of the sugar glider (Petaurus breviceps), an omnivorous marsupial, on a honey-pollen diet. Physiological Zoology, 60, 82-92.

Sommerville, D. (2005). Fat bees, skinny bees - a manual on honey bee nutrition for beekeepers. Kingston, ACT, Australia: Rural Industries Research and Development Corporation.

Storlien, L. H., Higgins, J. A., Thomas, T. C., Brown, M. A., Wang, H. Q., Haung, X. F., \& Else, P. L. (2000). Diet composition and insulin action in animal models. British Journal of Nutrition, 83(Suppl. 1), S85-S90.

Szczęsna, T. (2006). Protein content and amino acid composition of bee-collected pollen from selected botanical origins. Journal of Apicultural Science, 50, 81-90.

van Tets, I. G., \& Hulbert, A. J. (1999). A comparison of the nitrogen requirements of the eastern pygmy possum, Cercartetus nanus, on a pollen and on a mealworm diet. Physiological Biochemistry and Zoology, 72, 127-137.

van Tets, I. G., \& Whelan, R. J. (1997). Banksia pollen in the diet of Australian mammals. Ecography, 20, 399-505. 
Tables and figures

Table 1

Calculated (Zootrition ${ }^{\mathrm{TM}}$ Dietary Software v2.7, St. Louis, USA) nutrient composition of suggested vegetable/fruit mixtures fed to sugar gliders (Petaurus breviceps) following the Critter Love $₫$ diet plan (www.Critter Lovedietcenter.com). All nutrients, except water, are presented on a dry matter basis ME, metabolizable energy.

\begin{tabular}{|c|c|c|c|}
\hline \multirow[b]{2}{*}{ Nutrient } & \multicolumn{3}{|l|}{ Produce } \\
\hline & Mix 1 & Mix 2 & Mix 3 \\
\hline Water, \% & 89.2 & 87.5 & 88.9 \\
\hline Energy, $\mathrm{kJ} \mathrm{ME} / \mathrm{g}$ & 14.2 & 14.2 & 14.2 \\
\hline Total Dietary Fibre, $\%$ & 22.5 & 20.9 & 22.1 \\
\hline Crude fat, $\%$ & 2.2 & 2.4 & 2.5 \\
\hline Crude protein, $\%$ & 15.7 & 14.4 & 15.9 \\
\hline Ash, \% & 5.4 & 5.3 & 5.0 \\
\hline Vit $A$, IU or $R E / g^{*}$ & 114.0 & 188.0 & 144.7 \\
\hline Vit D3, IU/g & $\mathrm{NA}^{\circ}$ & NA & NA \\
\hline Vit $E, I U / g$ & 42.8 & 57.1 & 20.3 \\
\hline Vit C, mg/kg & $3,383.9$ & $2,733.5$ & $2,425.5$ \\
\hline Calcium, \% & 0.3 & 0.3 & 0.3 \\
\hline Magnesium, \% & 0.1 & 0.1 & 0.1 \\
\hline Phosphorus, \% & 0.3 & 0.2 & 0.3 \\
\hline Potassium, $\%$ & 1.8 & 1.6 & 1.6 \\
\hline Sodium, \% & 0.3 & 0.2 & 0.3 \\
\hline Copper, mg/kg & 4.8 & 5.0 & 5.4 \\
\hline Iron, mg/kg & 57.0 & 66.6 & 60.7 \\
\hline Manganese, $\mathrm{mg} / \mathrm{kg}$ & 22.4 & 13.3 & 24.0 \\
\hline Selenium, mg $/ \mathrm{kg}$ & 0.1 & 0.0 & 0.0 \\
\hline Zinc, mg/kg & 21.5 & 19.4 & 22.7 \\
\hline
\end{tabular}

Table 2

Analysed chemical composition of diet components and select commercially available ingredients fed to sugar gliders (Petaurus breviceps). All nutrients except water are presented on a dry matter basis $\mathrm{ADF}$, acid detergent fibre; NDF, neutral detergent fibre; NFC, non-fibre carbohydrates $=100-($ ash + fat + protein $+\mathrm{NDF}$ ); sugar (simple sugar) $=80 \%$ ethanol-soluble carbohydrates; $\mathrm{WSC}$, water-soluble carbohydrates (includes organic acids, soluble fibre and longer-chain fermentable fructans and oligosaccharides); NA, not analysed; ME, metabolizable energy. 


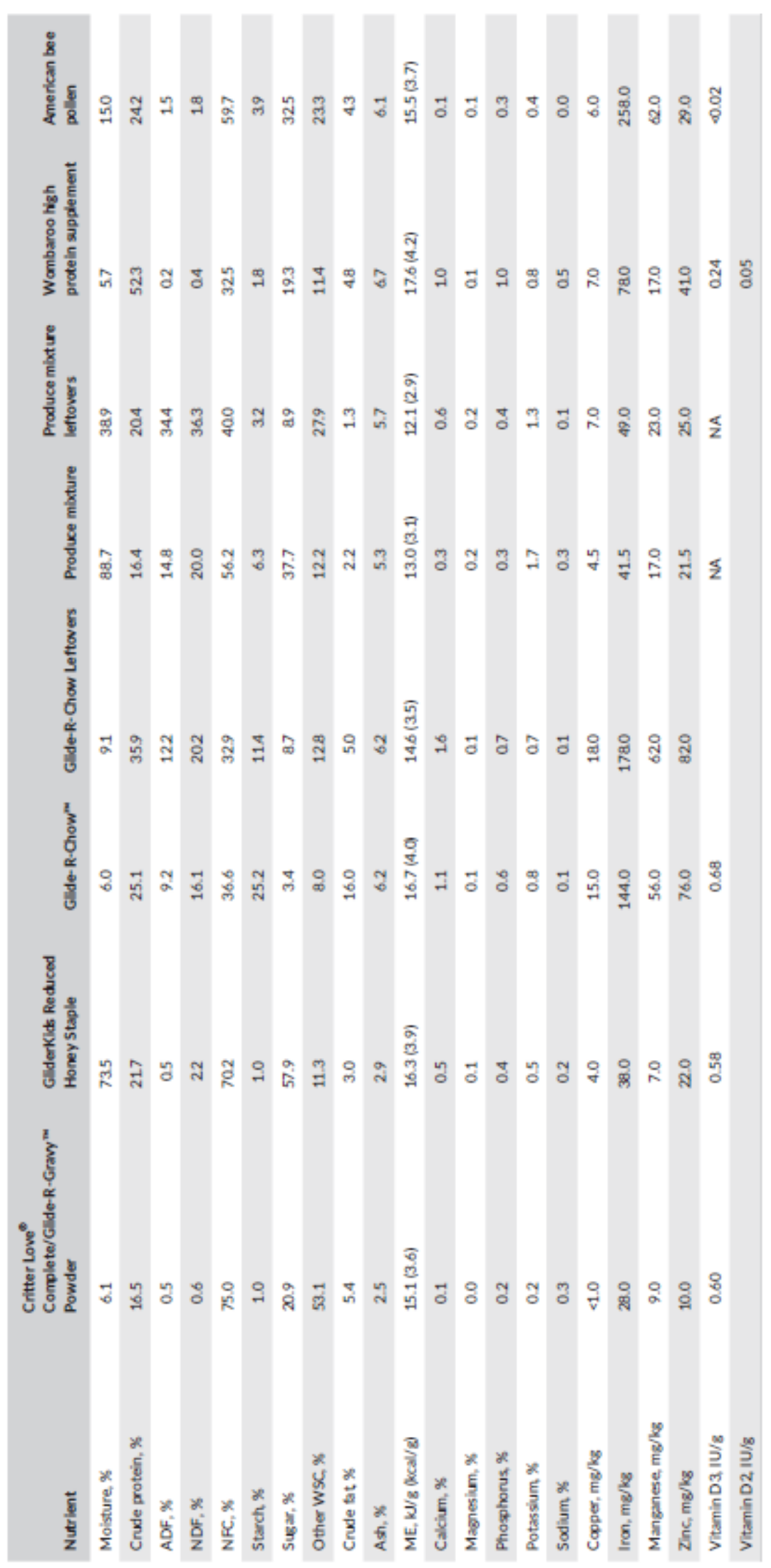




\section{Table 3}

Amino acid analyses of commercial products fed to sugar gliders (Petaurus breviceps), with select comparisons to published values for other bee pollens. Bolded indicates essential amino acid.

Underlined values indicate $<60 \%$ of requirement established for growing laboratory rat (NRC, 1995) NA, not analysed.

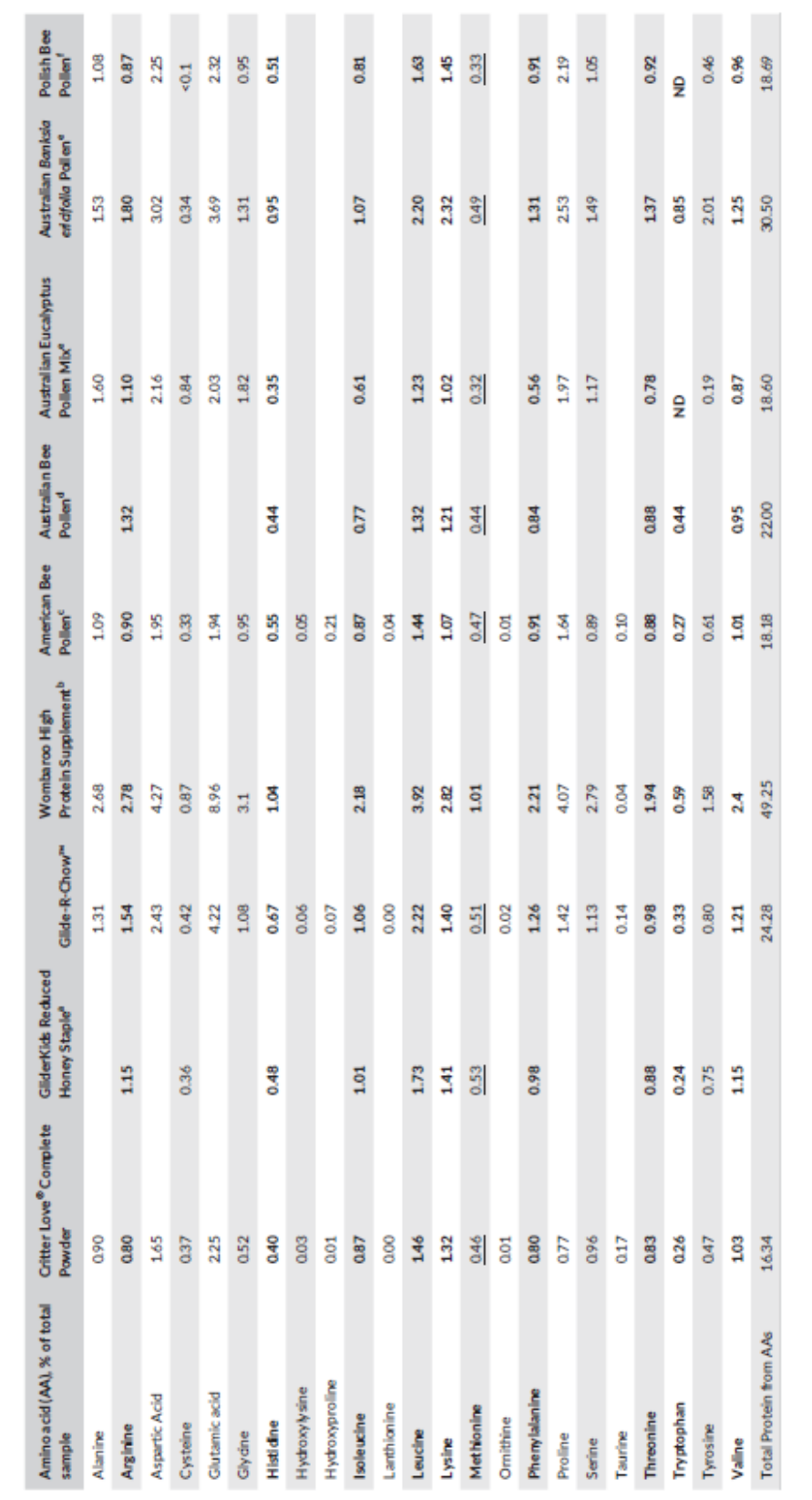

${ }^{\text {a }}$ Calculated values from raw ingredients.

${ }^{\mathrm{b}}$ Amino acid data provided by Wombaroo Food Products, Mt. Barker, Australia.

${ }^{c}$ Average value from two commercial samples analysed.

${ }^{d}$ Recalculated from data reported on 44 Eucalyptus spp. and 109 samples; Sommerville, 2005.

${ }^{\text {e }}$ Recalculated from data reported by van Tets \& Hulbert, 1999.

${ }^{\mathrm{f}}$ From 14 spp. and two additional botanical families; Szczęsna, 2006; . 
Table 4

Nutrient composition of three diets fed to sugar gliders (Petaurus breviceps), and suggested nutrient target ranges for maintenance and breeding (based on extrapolation from laboratory ratsa, as well as published values for gums and arthropods ( $\mathrm{N}, \mathrm{Mn}$ ) consumed in natureb). All nutrients except water presented on a dry matter basis; calculated values are designated as such ADF, acid detergent fibre; NDF, neutral detergent fibre; NFC, non-fibre carbohydrates $=100-($ ash + fat + protein + NDF $)$; sugar $($ simple sugar $)=80 \%$ ethanol-soluble carbohydrates; WSC, water-soluble carbohydrates (includes organic acids, soluble fibre and longer-chain fermentable fructans and oligosaccharides); NA, not applicable; ME, metabolizable energy; UNK, unknown.

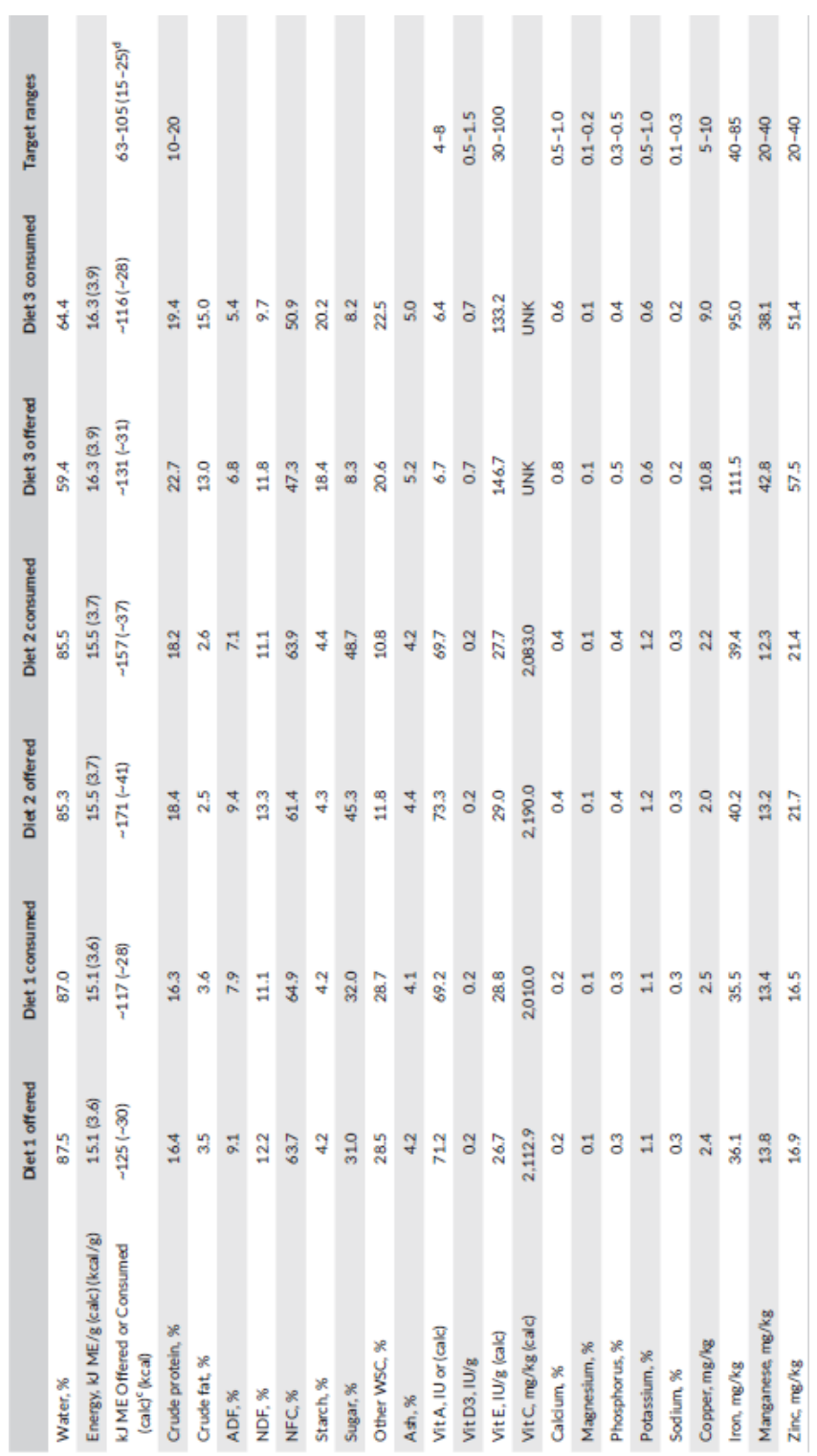

${ }^{a}$ NRC (1995) and Booth (2000).

${ }^{\mathrm{b}}$ Nagy \& Suckling, 1985.

${ }^{c}$ Per pair of animals weighing $\sim 70-90$ g each

${ }^{\mathrm{d}}$ Per individual glider; energy needs variable dependent upon body size, environment, physiologic state and activity levels. 


\section{Table 5}

Amino acid analyses of three diets fed to/consumed by captive sugar gliders (Petaurus breviceps). Bolded indicates essential amino acid. Underlined values indicate $<60 \%$ of requirement established for growing laboratory rat (NRC, 1995)

\begin{tabular}{|c|c|c|c|c|c|c|}
\hline \multirow[b]{2}{*}{ Amino acid, $\%$ of total sample } & \multicolumn{2}{|l|}{ Diet 1} & \multicolumn{2}{|l|}{ Diet 2} & \multicolumn{2}{|l|}{ Diet 3} \\
\hline & Offered & Consumed & Offered & Consumed & Offered & Consumed \\
\hline Arginine & 0.85 & 0.85 & 0.77 & 0.76 & 1.35 & 1.29 \\
\hline Cysteine & 0.22 & 0.22 & 0.14 & 0.14 & 0.41 & 0.41 \\
\hline Histidine & 0.33 & 0.33 & 0.27 & 0.27 & 0.60 & 0.58 \\
\hline Isoleucine & 0.69 & 0.70 & 0.56 & 0.56 & 1.01 & 1.00 \\
\hline Leucine & 1.08 & 1.09 & 0.85 & 0.85 & 2.02 & 1.97 \\
\hline Lysine & 1.00 & 1.02 & 0.80 & 0.80 & 1.38 & 1.37 \\
\hline Methionine' & $\underline{0.28}$ & $\underline{0.29}$ & $\underline{0.22}$ & $\underline{0.22}$ & $\underline{0.50}$ & $\underline{0.49}$ \\
\hline Phenylalanine & 0.62 & 0.62 & 0.50 & 0.50 & 1.14 & 1.11 \\
\hline Taurine & 0.07 & 0.07 & 0.00 & 0.00 & 0.15 & 0.15 \\
\hline Threonine & 0.65 & 0.65 & 0.51 & 0.51 & 0.94 & 0.93 \\
\hline Tryptophan & 0.19 & 0.19 & 0.13 & 0.13 & 0.31 & 0.31 \\
\hline Tyrosine & $p .37$ & 0.37 & 0.34 & 0.34 & 0.71 & 0.69 \\
\hline Valine & 0.79 & 0.80 & 0.63 & 0.63 & 1.16 & 1.15 \\
\hline
\end{tabular}

${ }^{a}$ Evaluated against requirement of methionine plus cysteine.

Table 6

Intake (as fed and dry matter (DM)), faecal output and apparent DM digestibility in pair-housed sugar gliders (Petaurus breviceps) fed one of three diets (means \pm SD)

\begin{tabular}{|c|c|c|c|c|}
\hline Diet treatment & $\begin{array}{l}\text { Daily amt offered } \\
\text { per pair (As Fed) }\end{array}$ & $\%$ Eaten & $\begin{array}{l}\text { Daily DM consumed } \\
\text { per pair }\end{array}$ & $\begin{array}{l}\text { Amt (g) or \% } \\
\text { per pair }\end{array}$ \\
\hline \multicolumn{5}{|l|}{ Diet 1} \\
\hline Critter Love ${ }^{\circledast}$ complete and water, g & $20.0 \pm 2.1$ & 100 & $3.3 \pm 0.6$ & \\
\hline Produce mixture, $g$ & $44.1 \pm 1.6$ & 92 & $4.4 \pm 0.2$ & \\
\hline Total, g & $64.1 \pm 2.9$ & 95 & $7.7 \pm 0.7$ & \\
\hline Diet as $\%$ body weight & $44.3 \pm 6.6^{\mathrm{a}}$ & & $5.6 \pm 1.1^{\mathrm{a}}$ & \\
\hline Daily faecal production, $\mathrm{g}$ dry & & & & $0.7 \pm 0.1$ \\
\hline Apparent digestibility, dry matter, \% & & & & $91 \pm 2^{\mathrm{a}}$ \\
\hline \multicolumn{5}{|l|}{ Diet 2} \\
\hline GliderKids low honey staple, g & $14.3 \pm 0.6$ & 100 & $3.8 \pm 0.2$ & \\
\hline Produce mixture, $g$ & $60.6 \pm 0.9$ & 87 & $6.3 \pm 0.1$ & \\
\hline Total & $74.9 \pm 0.8$ & 92 & $10.1 \pm 0.2$ & \\
\hline Diet as $\%$ body weight & $47.1 \pm 5.3^{\mathrm{a}}$ & & $7.2 \pm 0.8^{b}$ & \\
\hline Daily faecal production, $\mathrm{g}$ dry & & & & $1.3 \pm 0.2$ \\
\hline Apparent digestibility, dry matter, \% & & & & $87 \pm 2^{b}$ \\
\hline \multicolumn{5}{|l|}{ Diet 3} \\
\hline Glide-R-Gravy ${ }^{\mathrm{TM}}$ and water, $\mathrm{g}$ & $16.6 \pm 1.1$ & 100 & $2.9 \pm 0.2$ & \\
\hline Glide-R-Chow ${ }^{T M}, g$ & $7.5 \pm 0.1$ & 71 & $4.8 \pm 0.9$ & \\
\hline Total, g & $24.1 \pm 1.0$ & 89 & $7.7 \pm 1.0$ & \\
\hline Diet as $\%$ body weight & $13.5 \pm 1.3^{\mathrm{b}}$ & & $4.2 \pm 0.5^{\mathrm{a}}$ & \\
\hline Daily faecal production, $\mathrm{g}$ dry & & & & $1.0 \pm 0.3$ \\
\hline Apparent digestibility, dry matter, \% & & & & $89 \pm 2^{\mathrm{ab}}$ \\
\hline
\end{tabular}

Different superscripts within columns differ significantly $(\mathrm{p}<.05)$. 


\section{Table 7}

Composition of faecal samples from 5-day diet trials with sugar gliders (Petaurus breviceps) fed three diets, and calculated nutrient digestion coefficients. Mean \pm SD $(n=3$ pooled samples from four animals per diet)

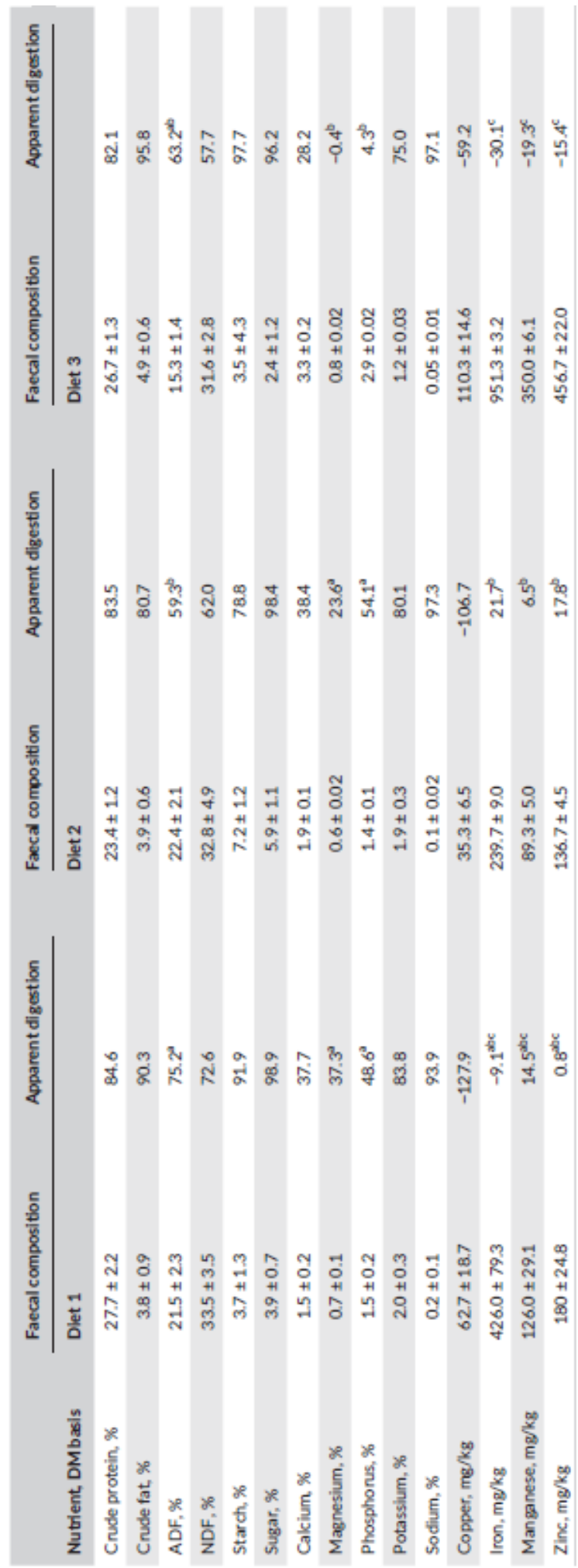

Differing superscripts within a row indicate significant differences $(\mathrm{p}<.05)$. 
Figure 1

Analytical evidence of nutrient selectivity by sugar gliders in a mixed diet (CP, crude protein; SO, soluble organic material not analysed in other fractions)

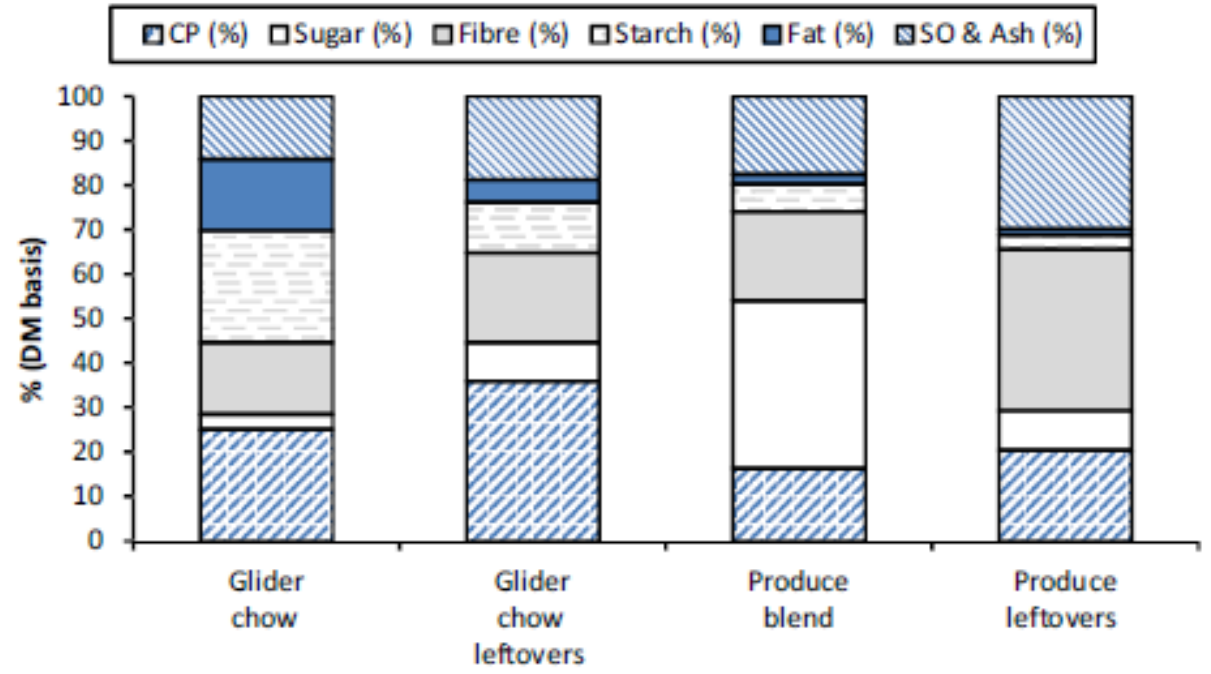

Figure 2

Change in total body weights $(\mathrm{BW}, \mathrm{g})$ for sugar gliders fed three different diets over 5-day intake trials

Diet 1 घDiet 2 Diet 3

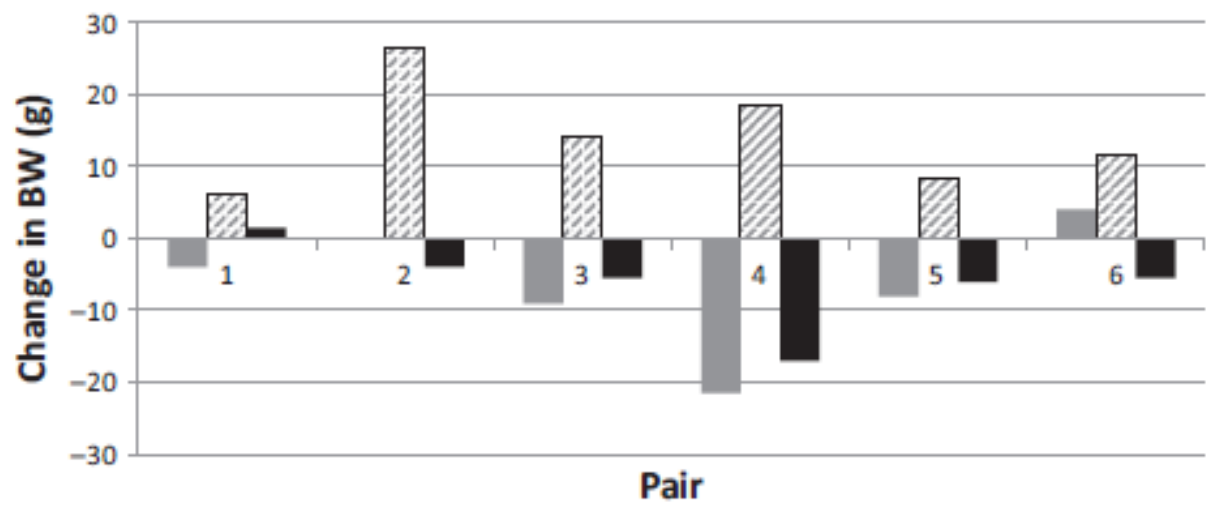

